\title{
Factors associated with carotid intima-media thickness in patients on maintenance hemodialysis
}

\section{RA Tuty Kuswardhani' Ketut Gede Wiradharma ${ }^{2}$ Yenny Kandarini ${ }^{3}$ Gde Raka Widiana ${ }^{3}$ Elysanti Dwi Martadiani ${ }^{4}$}

'Division of Geriatric Medicine, Department of Internal Medicine, Faculty of Medicine, Udayana University, Sanglah Hospital, Denpasar, Indonesia; ${ }^{2}$ Department of Internal Medicine, Sumbawa District Hospital, Sumbawa Besar, Indonesia; ${ }^{3}$ Division of Nephrology, Department of Internal Medicine, Faculty of Medicine, Udayana University, Sanglah Hospital, Denpasar, Indonesia; ${ }^{4}$ Department of Radiology, Faculty of Medicine, Udayana University, Sanglah Hospital, Denpasar, Indonesia
Correspondence: RA Tuty Kuswardhani Division of Geriatric Medicine, Department of Internal Medicine, Faculty of Medicine, Udayana University, Sanglah Hospital, Jl. Diponegoro, Dauh Puri Klod, Denpasar 80II3, Bali, Indonesia Email tutykuswardhani@yahoo.com
This article was published in the following Dove Press journal: International Journal of General Medicine

Purpose: The aim of this study was to analyze the association of the carotid intima-media thickness (CIMT) with various parameters in patients on maintenance hemodialysis (mHD).

Methods: A cross-sectional study was conducted, enrolling 68 subjects (41 men, 27 women) on mHD in the Hemodialysis Unit, Sanglah Hospital, Denpasar, Indonesia. CIMT was measured with B-mode ultrasonography using a USG Sonoace 8000 and a $7.5 \mathrm{MHz}$ linear transducer.

Results: CIMT was higher in subjects with cardiovascular disease (CVD) compared with those without CVD (0.6494 vs $0.7288 \mathrm{~mm} ; P=0.026)$, and in men compared with women ( $0.7056 \mathrm{vs}$ $0.6141 \mathrm{~mm} ; P=0.003)$. CIMT was correlated with age $(R=0.607 ; P<0.001)$, plasma albumin ( $R=-0.291, P=0.016)$, serum phosphate $(R=-0.294, P=0.015)$, calcium-phosphate product $(R=-0.284, P=0.011)$, and plasma high-sensitivity $\mathrm{C}$-reactive protein $(R=0.279, P=0.030)$. However, after multiple linear regression testing, only age consistently had a role in determining the CIMT value $(\beta=0.452, P<0.001)$.

Conclusion: Subjects with CVD have higher CIMT than those without CVD and men had higher CIMT than women. In addition, older age, higher high-sensitivity C-reactive protein, and lower albumin, phosphate, and calcium-phosphate product levels were correlated with higher CIMT. Age was the most important marker for CIMT in subjects on mHD.

Keywords: carotid intima-media thickness, hemodialysis, age

\section{Introduction}

Cardiovascular disease (CVD) remains the leading cause of morbidity and mortality in most countries worldwide. Meanwhile, chronic kidney disease (CKD) is recognized as a health concern globally and causes increased number of death as well as health care expenditure. CKD itself is an independent risk factor for CVD; both traditional and nontraditional risk factors for CVD exist in CKD patients. ${ }^{1}$ In review articles on CVD in patients with CKD, Wright and Hutchison ${ }^{2}$ and Ritz and Bommer ${ }^{3}$ stated that patients with CKD or on hemodialysis (HD) have markedly reduced life expectancy due to higher mortality from CVD compared with those with normal kidney function. Furthermore, they noted that CVD and CKD are linked by common risk factors or etiology and together lead to a poor prognosis. Atherosclerosis and vascular calcification were more prevalent in patients on dialysis than in controls. ${ }^{4}$ In the Cardiovascular Outcomes Registry in Dialysis Patients (CORDIAL) study, the prevalence of cardiovascular risk factors in HD patients was $87.5 \%$ for hypertension, $84.7 \%$ for dyslipidemia, $73.1 \%$ for sedentary lifestyle, $53.7 \%$ for tobacco use, and $35.8 \%$ for diabetes. ${ }^{5}$ 
Carotid intima-media thickness (CIMT) is associated with several risk factors for CVD. It has been suggested to be an important marker of atherosclerotic vascular disease and is predictive of cardiovascular events in the future independent of age, gender, and risk factors for CVD. ${ }^{6}$ CIMT testing is a safe, noninvasive, and cost-effective method to detect early CVD. ${ }^{7}$ CIMT increases with advancing coronary artery disease; patients with mean CIMT over $1.15 \mathrm{~mm}$ have a $94 \%$ likelihood of having coronary artery disease. ${ }^{8}$ Although many studies have shown that changes in CIMT predict future cardiovascular events, the value of CIMT testing in CVD risk assessment is still vigorously debated. ${ }^{9}$

CIMT is related to several traditional and nontraditional risk factors for CVD in patients with CKD, both in non-HD and in maintenance HD (mHD). ${ }^{10}$ Carotid atherosclerosis is associated with inflammation, malnutrition (hypoalbuminemia), and intracellular adhesion molecule-1 in patients on ambulatory peritoneal dialysis (PD). ${ }^{11}$ In CKD patients, CIMT examination can be used as a surrogate measure to assess the incidence and severity of arterial medial calcification. ${ }^{12} \mathrm{CIMT}$ is a strong predictor of CVD in Chinese predialysis patients and may be useful for risk stratification in this group of patients. ${ }^{13}$

Since the pathogenesis of the diseases is influenced by genetic or ethnicity and environmental factors, and there are no data on CIMT in patients with CKD in Indonesia, we conducted this study. In this study, we analyzed the associations between several clinical and biochemical parameters as risk factors for CVD and CIMT in patients with $\mathrm{mHD}$.

\section{Methods}

A cross-sectional study was conducted during May and June 2016 in the Hemodialysis Unit, Sanglah Hospital, Denpasar, Indonesia. All eligible subjects (aged 26-80 years) on the period were included in this study. Sixty-eight subjects undergoing $\mathrm{mHD}$ for any underlying disease who met the criteria of this study were enrolled. Subjects with mHD were defined by subjects who were undergoing HD twice a week for 4.5 hours per HD for at least 3 months. Subjects with malignancy, severe anemia (hemoglobin $<6 \mathrm{mg} / \mathrm{dL}$ ), cigarette smoking, systemic lupus erythematosus, acute infection, liver function abnormality, or long-term steroid therapy, which influence the study parameters, were excluded.

Several clinical and biochemical parameters, including age, gender, body mass index, waist circumference, blood pressure, duration on HD, history of diabetes, coronary heart disease (CHD), stroke, peripheral arterial disease (PAD), statin use, complete blood count, lipid profile, total calcium and phosphate serum, calcium-phosphate product, albumin plasma, IL-6, high-sensitivity C-reactive protein (hs-CRP), and CIMT were recorded and measured.

Diagnosis of diabetes (defined by Criteria of American Diabetes Association ${ }^{14}$ by endocrinologist), CHD (defined by cardiologist based on guidelines of American College of Cardiology Foundation/American Heart Association Task Force on Practice Guidelines, and the American College of Physicians, American Association for Thoracic Surgery, Preventive Cardiovascular Nurses Association, Society for Cardiovascular Angiography and Interventions, and Society of Thoracic Surgeons), ${ }^{15}$ stroke (defined by neurologist based on Guideline for Healthcare Professionals from the American Heart Association/American Stroke Association), ${ }^{16}$ PAD was defined if ankle-brachial index was $<0.9$, and statin use was drawn from medical record. Subjects with CHD, and/or stroke and/or PAD were grouped into subjects with CVD.

Complete blood count was measured by flow cytometry method (Cell-Dyn RUBY), plasma cholesterol was measured by homogenous enzymatic colorimetric assay (Cobas c501), plasma triglyceride was measured by enzymatic calorimetric test (Cobas c501), serum calcium was measured by spectrophotometry (Cobas c501), and phosphate was measured by Molybdate UV (Cobas c501). Calcium-phosphate product was calculated by multiplying calcium and phosphate levels $\left(\mathrm{mg}^{2} /\right.$ dL). ${ }^{2}$ Albumin-adjusted (corrected) calcium was calculated by formula: $(0.8 \times$ [4-patient's albumin $\mathrm{g} / \mathrm{dL}]+$ serum total calcium level in $\mathrm{mg} / \mathrm{dL}$ ). Plasma albumin was measured by colorimetric assay (Cobas c501). IL-6 level was measured using the human IL-6 immunoassay method (Quantikine ${ }^{\circledR}$ HS Elisa kit ; R\&D Systems, Inc., Minneapolis, MN, USA). Plasma levels of hs-CRP were measured by the particle-enhanced immuneturbidimetric method (Cobas c501; cardiac CRP [Latex] high sensitive; Hoffman-La Roche Ltd., Basel, Switzerland). The measurement method for CIMT was based on a standard procedure described by several researchers. ${ }^{17-19}$ CIMT was evaluated by a consultant radiologist using B-mode ultrasonography with a USG Sonoace 8000 (Samsung Medison Co., Ltd., Seoul, Korea) and 7.5 MHz linear transducer. In this study, CIMT was measured at three points on each right and left carotid artery: at common carotid artery ( $1 \mathrm{~cm}$ from bifurcation), bifurcation, and internal carotid artery (1 cm from bifurcation). The mean CIMT was the sum of all values divided by six.

Data were expressed descriptively as in the baseline data, and the correlations between CIMT and all clinical and biochemical parameters were analyzed by Pearson's correlation test. Differences in mean CIMT between men and women, subjects with or without CVD, or in those with diabetes and statin use were analyzed by independent $t$-test; a multiple 
linear regression test was used to analyze the roles of several parameters in determining the CIMT value. In all statistical analyses, values of $P<0.005$ were considered to indicate significant difference or correlation between mean values.

\section{Ethical approval and consent to participate}

The study was approved by the Ethical Committee of the Faculty of Medicine, Udayana University and Sanglah Hospital (no. 561/UN.14.2/Litbang/2016), and it was authorized by the Director of Sanglah Hospital on 8 April, 2016 (no. LB.02.01./ II.C5.D11/6327/2016). All subjects were given information regarding this study and signed the informed consent. This study was conducted in accordance with the Declaration of Helsinki.

\section{Results}

This cross-sectional study enrolled 68 subjects on mHD, 41 men and 27 women, with an age range of 26-80 (mean 56.28) years. Parameters including history of CVD, clinical and biochemical parameters, and CIMT were measured and analyzed. Baseline data for all subjects are shown in Table 1. Men had significantly higher mean CIMT compared with women (0.7056 $\pm 0.1236 \mathrm{~mm}$ vs $0.6141 \pm 0.1167 \mathrm{~mm}, P=0.003)$, and subjects with CVD had higher CIMT values than those without CVD (0.7288 $\pm 0.1152 \mathrm{~mm}$ vs $0.6494 \pm 0.1272, P=0.026)$; there were no significant differences in mean CIMT between subjects with diabetes and statin use and those without ( $0.6863 \pm 0.1131$ vs $0.6640 \pm 0.1131, P=0.549 ; 0.6633 \pm 0.1130$ vs $0.6698 \pm 0.1304, P=0.907$, respectively; Table 2 ). The correlation test showed that age and hs-CRP were positively correlated with CIMT $(R=0.607, P<0.001 ; R=0.239, P=0.030$, respectively), while albumin plasma, phosphate serum, and calcium-phosphate product were negatively correlated with CIMT $(R=-0.291, P=0.016 ; R=-0.294, P=0.015 ; R=-0.284$, $P=0.019$, respectively). The strongest correlation was between age and CIMT (Table 3; Figure 1). In the multiple linear regression analysis, only age consistently had a role in determining the CIMT value $(\beta=0.452, P<0.001$; Table 4$)$.

\section{Discussion}

In this study, subjects on mHD with CVD were shown to have higher mean CIMT value than those without CVD. CIMT has been found to be higher in patients with end-stage renal disease than in healthy controls. ${ }^{20}$ In our study, men had higher CIMT values compared to women. In general, men have a higher prevalence of CVD than women of similar age. One study of an Iranian population by Pourafkari et al found that the mean CIMT in men was higher than that in women, ${ }^{21}$ and several studies have reported similar results. ${ }^{22,23}$
Table I Baseline data of patients $(\mathrm{N}=68)$

\begin{tabular}{|c|c|}
\hline Parameters & $\begin{array}{l}\text { Frequency or Mean } \\
\pm \text { SD }\end{array}$ \\
\hline \multicolumn{2}{|l|}{ Gender } \\
\hline Male/female & $41 / 27$ \\
\hline Diabetes & $16 / 68(23.52 \%)$ \\
\hline CVD & $17 / 68(25.00 \%)$ \\
\hline $\mathrm{CHD}$ & $10 / 68(14.70 \%)$ \\
\hline Stroke & $9 / 68(13.23 \%)$ \\
\hline PAD & $2 / 68(2.94 \%)$ \\
\hline Statin user & $6 / 68(8.82 \%)$ \\
\hline Age (years) & $56.28 \pm I 1.794$ \\
\hline Duration on HD (months) & $50.46 \pm 32.35$ \\
\hline \multicolumn{2}{|l|}{ Systolic blood pressure $(\mathrm{mmHg})$} \\
\hline Standing & $148.58 \pm 24.49$ \\
\hline Sitting & $148.60 \pm 24.55$ \\
\hline Lying & $148.68 \pm 24.24$ \\
\hline \multicolumn{2}{|l|}{ Diastolic blood pressure $(\mathrm{mmHg})$} \\
\hline Standing & $85.22 \pm 11.85$ \\
\hline Sitting & $85.29 \pm 12.02$ \\
\hline Lying & $86.32 \pm 10.49$ \\
\hline Body mass index $\left(\mathrm{kg} / \mathrm{m}^{2}\right)$ & $22.2 \mathrm{I} \pm 4.28$ \\
\hline Waist circumference $(\mathrm{cm})$ & $85.13 \pm 12.43$ \\
\hline Hemoglobin (g/dL) & $9.87 \pm 1.66$ \\
\hline White blood cells $\left(10^{3} / \mathrm{mm}^{3}\right)$ & $7.65 \pm 2.07$ \\
\hline Neutrophils $\left(10^{3} / \mathrm{mm}^{3}\right)$ & $4.87 \pm 1.59$ \\
\hline Lymphocytes $\left(10^{3} / \mathrm{mm}^{3}\right)$ & $1.60 \pm 0.65$ \\
\hline Monocytes $\left(10^{3} / \mathrm{mm}^{3}\right)$ & $0.56 \pm 0.18$ \\
\hline Total cholesterol (mg/dL) & $|64.24 \pm 38.6|$ \\
\hline LDL cholesterol (mg/dL) & $104.73 \pm 33.70$ \\
\hline HDL cholesterol (mg/dL) & $39.36 \pm 13.45$ \\
\hline Triglycerides (mg/dL) & $156.36 \pm 90.38$ \\
\hline Albumin plasma $(\mathrm{g} / \mathrm{dL})$ & $4.03 \pm 0.36$ \\
\hline Calcium (mg/dL) & $9.01 \pm 0.66$ \\
\hline Albumin-adjusted calcium (mg/dL) & $8.98 \pm 0.70$ \\
\hline Phosphate (mg/dL) & $9.01 \pm 0.66$ \\
\hline Calcium-phosphate product $\left(\mathrm{mg}^{2} / \mathrm{dL}^{2}\right)$ & $51.15 \pm 18.64$ \\
\hline IL-6 serum $(\mathrm{pg} / \mathrm{mL})$ & $5.09 \pm 3.36$ \\
\hline hs-CRP serum (mg/L) & $8.95 \pm 28.45$ \\
\hline $\mathrm{CIMT}(\mathrm{mm})$ & $0.67 \pm 0.13$ \\
\hline
\end{tabular}

Abbreviations: CHD, coronary heart disease; CIMT, carotid intima-media thickness; CVD, cardiovascular disease; HD, hemodialysis; HDL, high-density lipoprotein; hs-CRP, high-sensitivity C-reactive protein; LDL, low-density lipoprotein; PAD, peripheral arterial disease.

Inflammation has an important role in the mechanism of atherosclerosis. Some inflammatory markers such as IL-6 and hs-CRP are well-known risk factors for atherosclerotic vascular diseases. ${ }^{24}$ In this study, we found that levels of hsCRP, but not IL-6, were associated with CIMT. IL-6 level in blood likely does not reflect the action in general, because it also acts as paracrine. Levels of CRP have been found to be higher in CKD patients on $\mathrm{MHD}$ and PD compared with healthy controls $\left(9.2,8.37\right.$, and $3.89 \mathrm{~g} / \mathrm{L}$, respectively). ${ }^{25}$ Age is an important risk factor for atherosclerotic CVD. In our study, age had the strongest correlation with CIMT and 
Table 2 Mean CIMT by gender and clinical status

\begin{tabular}{|l|l|l|}
\hline Parameters & Mean \pm SD & P-value \\
\hline Gender & & \\
Male & $0.7056 \pm 0.1236$ & $0.003^{*}$ \\
Female & $0.6141 \pm 0.1167$ & \\
CVD & & \\
No & $0.6494 \pm 0.1272$ & $0.026^{*}$ \\
Yes & $0.7288 \pm 0.1152$ & \\
Diabetes & & \\
No & $0.6640 \pm 0.1131$ & 0.549 \\
Yes & $0.6863 \pm 0.1131$ & \\
Statins user & & \\
No & $0.6698 \pm 0.1304$ & 0.907 \\
Yes & $0.6633 \pm 0.1130$ & \\
\hline
\end{tabular}

Note: *Statistically significant.

Abbreviations: CIMT, carotid intima-media thickness, CVD, cardiovascular disease.

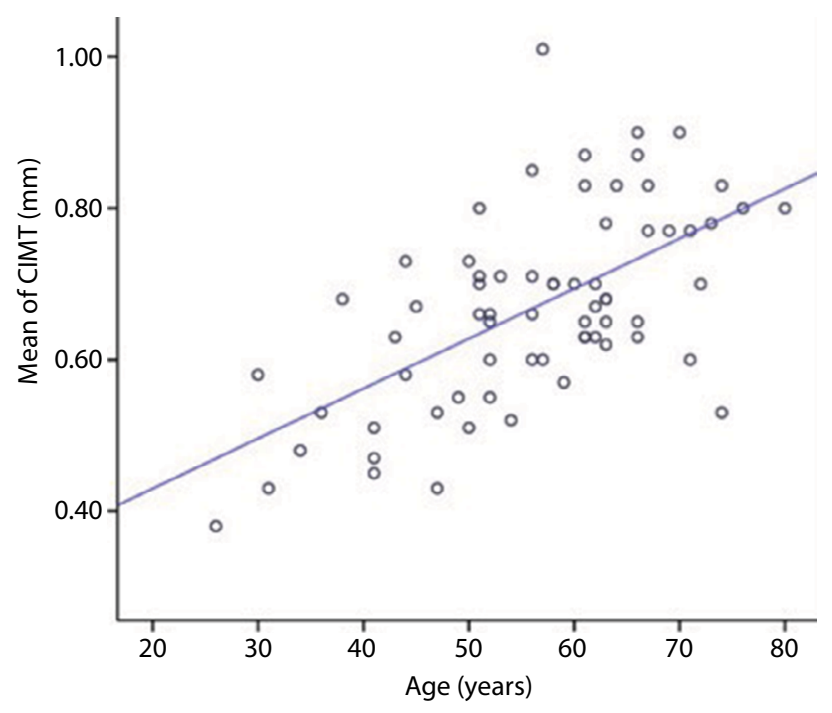

Figure I Correlation between age and CIMT.

Abbreviation: CIMT, carotid intima-media thickness.

was one of the most consistent markers for CIMT. Older patients (over 60 years) had higher CIMT compared with the younger (20-29 years) group $(0.305 \mathrm{~mm}$ vs $0.645 \mathrm{~mm}){ }^{21}$ A cohort study enrolling 2,580 subjects found an increased CIMT reference range within different age strata. ${ }^{26}$ In addition, CIMT was found to increase with age and low-density lipoprotein level, whereas it decreased with high-density lipoprotein levels and was lower in White individuals. ${ }^{27}$ In a study on association of CIMT and inflammation and traditional cardiovascular risk factors in nondialysis-dependent patients with CKD, CIMT was found to be correlated with age $(R=0.538, P<0.001)$, waist circumference $(R=0.235$, $P=0.016), \mathrm{CRP}(R=0.191, P=0.035)$, and SBP $(R=0.181$, $P=0.048)$. According to multiple regression analysis, the independent determinants of CIMT were age $(\beta=0.512$, $P<0.001)$ and CRP levels $(\beta=0.159, P=0.041) .{ }^{22}$ In mHD patients, CIMT was positively correlated with age $(R=0.247$, $P=0.032$ ) and other traditional risk factors (SBP, mean arterial blood pressure, and pulse rate). ${ }^{10}$ In this study, our bivariate analysis showed that age and levels of hs-CRP, albumin, phosphate, and calcium-phosphate products were correlated with CIMT, but after analysis by the multiple regression test, only age consistently influenced the CIMT value. The findings of our study are similar to those of other studies showing that age is the strongest marker of CIMT in CKD.

Albuminuria is an important risk factor for CVD and leads to an increase in all-cause mortality in patients with diabetes or hypertension, and in the general population. ${ }^{1}$ Low levels of plasma albumin are related to severe albuminuria and/ or malnutrition in patients with CKD. In this study, serum 
Table 4 Role of various risk factors for CIMT

\begin{tabular}{|l|l|l|l|l|l|l|}
\hline \multirow{2}{*}{ Model I } & Unstandardized coefficients & \multicolumn{3}{l|}{ Standardized coefficients } & 95\% CI for B \\
\cline { 2 - 7 } & B & Std. error & B & t & Sig. \\
\hline Constant & 0.342 & 0.232 & 1.472 & 3.749 & 0.147 & -0.124 to 0.807 \\
\hline Age & 0.006 & 0.002 & 0.452 & 0.156 & $<0.00 I^{*}$ & 0.003 to 0.009 \\
\hline Albumin & 0.007 & 0.047 & 0.023 & - & 0.877 & 0.088 to 0.103 \\
\hline Phosphate & -0.022 & 0.036 & -0.370 & 0.608 & 0.546 & 0.095 to 0.05 I \\
\hline Calcium-phosphate product & 0.002 & 0.004 & 0.273 & 0.455 & 0.65 I & 0.006 to 0.010 \\
\hline hs-CRP & 0.001 & 0.001 & 0.212 & 1.536 & 0.130 & 0.000 to 0.002 \\
\hline
\end{tabular}

Note: *Statistically significant.

Abbreviations: CIMT, carotid intima-media thickness; hs-CRP, high-sensitivity C-reactive protein.

albumin level was negatively correlated with the CIMT value. Subjects with lower plasma albumin levels in this study might have had more severe albuminuria or lower protein intake. A study by Helal et al showed that patients with CKD on HD and PD had lower levels of albumin compared with the control group $\left(31.5,28.83\right.$, and $46.7 \mathrm{mmol} / \mathrm{L}$, respectively). ${ }^{25}$ Early disorders of mineral metabolism may occur in CKD. As the glomerular filtration rate value declines, there is a decrease in serum calcium levels and an increase in levels of parathyroid hormone and phosphate. High levels of serum phosphorus in patients with end-stage renal disease were found to be significant and an independent risk factor of all-cause and cardiovascular mortality and vascular calcification. ${ }^{1,28}$ High serum phosphate is a significant and independent factor associated with advanced atherosclerosis in CKD patients with or without diabetes, in addition to advanced age. ${ }^{29}$ Calcium-phosphate products are also associated with an increased risk of cardiovascular morbidity and mortality in patients with CKD. The underlying pathogenesis of how increased serum phosphate and calcium-phosphate products cause CVD is not well established. ${ }^{1,28}$ Potential mechanisms by which hyperphosphatemia has a direct effect on vascular calcification are suggested by modulation of key hormones fibroblast growth factor- 23 and calcitriol. ${ }^{30}$ One study in mHD patients revealed that CIMT was positively correlated with serum phosphate $(R=0.604, P<0.01)$ and calcium-phosphate product $(R=0.048, P<0.01)$, and negatively correlated with serum albumin $(R=-0.292, P=0.011) .{ }^{10}$ A study by Ishimura et al also showed that serum phosphate was positively correlated with CIMT in HD patients. ${ }^{31}$

Renal factors such as calcium-phosphate product and hyperphosphatemia are the important risk factors for CVD in CKD. This study found, by contrast, that serum phosphate and calcium-phosphate product were negatively correlated with CIMT. However, although both parameters showed weak correlation with CIMT, they had no role after analysis by multiple regression test. We do not yet have any reason- able explanation for this finding. Only age was consistent as a marker for CIMT in this study. A limitation of this study was the fact that the data on coexisting diseases such as CVD (CHD, stroke, PAD) were based on medical records.

\section{Conclusion}

On the basis of the results of this study, it can be concluded that: 1) subjects with CVD have higher CIMT than those without CVD; 2) men have higher CIMT than women; 3) older age and higher hs-CRP, lower albumin and phosphate levels, and calcium-phosphate product are correlated with higher CIMT; and 4) age is the most important marker for CIMT in subjects on mHD.

\section{Acknowledgments}

The authors are grateful to all the patients who were involved in this study and to the staff at the Hemodialysis Unit for supporting this study. This work was partly financially supported by Sanglah Hospital and partly by the authors.

\section{Disclosure}

The authors report no conflicts of interest in this work.

\section{References}

1. Alani H, Tamimi A, Tamimi N. Cardiovascular co-morbidity in chronic kidney disease: Current knowledge and future research needs. World $J$ Nephrol. 2014;3(4):156-168.

2. Wright J, Hutchison A. Cardiovascular disease in patients with chronic kidney disease. Vasc Health Risk Manag. 2009;5:713-722.

3. Ritz E, Bommer J. Cardiovascular problems on hemodialysis: current deficits and potential improvement. Clin J Am Soc Nephrol. 2009;4 Suppl 1:S71-S78.

4. Coll B, Betriu A, Martínez-Alonso M, et al. Large artery calcification on dialysis patients is located in the intima and related to atherosclerosis. Clin J Am Soc Nephrol. 2011;6(2):303-310.

5. Burmeister JE, Mosmann CB, Costa VB, et al. Prevalence of cardiovascular risk factors in hemodialysis patients - The CORDIAL study. Arq Bras Cardiol. 2014;102(5):473-480.

6. Bauer M, Caviezel S, Teynor A, Erbel R, Mahabadi AA, SchmidtTrucksass A. Carotid intima-media thickness as a biomarker of subclinical atherosclerosis. Swiss Med Wkly. 2012;142:w13705. 
7. Kasliwal RR, Bansal M, Desai D, Sharma M. Carotid intima-media thickness: current evidence, practices, and Indian experience. Indian J Endocrinol Metab. 2014;18(1):13-22.

8. Kablak-Ziembicka A, Tracz W, Przewlocki T, Pieniazek P, Sokolowski A, Konieczynska M. Association of increased carotid intimamedia thickness with the extent of coronary artery disease. Heart. 2004;90(11):1286-1290.

9. Doneen AL, Bale BF. Carotid intima-media thickness testing as an asymptomatic cardiovascular disease identifier and method for making therapeutic decisions. Postgrad Med. 2013;125(2):108-123.

10. Kuang D, You H, Ding F, et al. Intima-media thickness of the carotid artery and its correlation factors in maintenance hemodialysis patients: a cross-sectional study. Blood Purif. 2009;28(3):181-186.

11. Papagianni A, Kokolina E, Kalovoulos M, Vainas A, Dimitriadis C, Memmos D. Carotid atherosclerosis is associated with inflammation, malnutrition and intercellular adhesion molecule- 1 in patients on continuous ambulatory peritoneal dialysis. Nephrol Dial Transplant. 2004;19(5):1258-1263.

12. Janda K, Krzanowski M, Gajda M, et al. Cardiovascular risk in chronic kidney disease patients: intima-media thickness predicts the incidence and severity of histologically assessed medial calcification in radial arteries. BMC Nephrol. 2015;16:78.

13. Szeto CC, Chow KM, Woo KS, et al. Carotid intima media thickness predicts cardiovascular diseases in Chinese predialysis patients with chronic kidney disease. J Am Soc Nephrol. 2007;18(6):1966-1972.

14. American Diabetes Association. 2. Classification and diagnosis of diabetes. Diabetes Care. 2016;39 Suppl 1:S13-S22.

15. Fihn SD, Gardin JM, Abrams J et al. ACCF/AHA/ACP/AATS/PCNA/ SCAI/STS Guideline for the diagnosis and management of patients with stable ischemic heart disease: executive summary: a report of the American College of Cardiology Foundation/American Heart Association Task Force on Practice Guidelines, and the American College of Physicians, American Association for Thoracic Surgery, Preventive Cardiovascular Nurses Association, Society for Cardiovascular Angiography and Interventions, and Society of Thoracic Surgeons. J Am Coll Cardiol. 2012;60(24):2564-2603.

16. Jauch JC, Saver JL, Adams HP et al. Guidelines for the early management of patients with acute ischemic stroke: a guideline for healthcare professionals from the American Heart Association/American Stroke Association. On behalf of the American Heart Association Stroke Council, Council on Cardiovascular Nursing, Council on Peripheral Vascular Disease, and Council on Clinical Cardiology. Stroke. 2013;44:870-947.

17. Baldassare D, Amato M, Bondiolai A, Sirtori CR, Tremoli E. Carotid artery intima-media thickness measured by ultrasonography in normal clinical practice correlates well with atherosclerotic risk factors. Stroke. 200 (31):2426-2430.
18. Simon A, Gariepy J, Chironi G, Megnien JL, Levenson J. Intima-media thickness: a new tool for diagnosis and treatment of cardiovascular risk. J Hypertens. 2002;20(2):159-169.

19. Ohya Y, Abe I, Fujii K, Kobayashi K, Onaka U, Fujishima M. Intimamedia thickness of the carotid artery in hypertensive subjects and hypertrophic cardiomyopathy patients. Hypertension. 1997;29(1 Pt 2): 361-365.

20. Kumar KS, Lakshmi AY, Srinivasa Rao PVLN, Das GC, Kumar VS. Carotid intima-media thickness in patients with end-stage renal disease. Indian J Nephrol. 2009;19(1):13-14.

21. Pourafkari M, Bhaktiyari ET, Jalali AH, Shakila M. Ultrasonic measurement of carotid intima-media thickness in a group of Iranian with no cardiovascular risk factors. Iran J Radiol. 2006;3(3):163-167.

22. Lemos MM, Jancikic AD, Sanches FM, et al. Intima-media thickness is associated with inflammation and traditional cardiovascular risk factors in non-dialysis-dependent patients with chronic kidney disease. Nephron Clin Pract. 2010;115(3):c189-c194.

23. Wu TW, Hung CL, Liu CC, Wu YJ, Wang LY, Yeh HI. Associations of cardiovascular risk factors with carotid intima-media thickness in middle-age Adults and Elders. J Atheroscler Thromb. 2017;24(7):677-686.

24. Okazaki S, Sakaguchi M, Miwa K, et al. Association of interleukin-6 with the progression of carotid atherosclerosis: a 9-year follow-up study. Stroke. 2014;45(10):2924-2929.

25. Helal I, Smaoui W, Hamida FB, et al. Cardiovascular risk factors in hemodialysis and peritoneal dialysis patients. Saudi J Kidney Dis Transpl. 2010;21(1):59-62.

26. Tosetto A, Prati P, Baracchini C, Manara R, Rodeghiero F. Age-adjusted reference limits for carotid intima-media thickness as better indicator of vascular risk: population-based estimates from the VITA project. J Thromb Haemost. 2005;3(6):1224-1230.

27. Preston E, Ellis MR, Kulinskaya E, Davies AH, Brown EA. Association between carotid artery intima-media thickness and cardiovascular risk factors in CKD. Am J Kidney Dis. 2005;46(5):856-862.

28. Kendrick J, Kestenbaum B, Chonchol M. Phosphate and cardiovascular disease. Adv Chronic Kidney Dis. 2011;18(2):113-119.

29. Sharma VK, Dwivedi P, Dubey AK, Budey AK. Correlation of serum phosphate with carotid intimal-medial thickness in chronic kidney disease patients. Indian J Nephrol. 2014;24(1):15-19.

30. Heine GH, Nangaku M, Fliser D. Calcium and phosphate impact cardiovascular risk. Eur Heart J. 2013;34(15):1112-1121.

31. Ishimura E, Taniwaki H, Tabata $\mathrm{T}$, et al. Cross-sectional association of serum phosphate with carotid intima-medial thickness in hemodialysis patients. Am J Kidney Dis. 2005;45(5):859-865.
International Journal of General Medicine

\section{Publish your work in this journal}

The International Journal of General Medicine is an international, peer-reviewed open-access journal that focuses on general and internal medicine, pathogenesis, epidemiology, diagnosis, monitoring and treatment protocols. The journal is characterized by the rapid reporting of reviews, original research and clinical studies across all disease areas.

\section{Dovepress}

The manuscript management system is completely online and includes a very quick and fair peer-review system, which is all easy to use. Visit http://www.dovepress.com/testimonials.php to read real quotes from published authors. 